\title{
Determination of optimum dosage of the mutagen ethyl methanesulphonate (EMS) for mass treatment of shoot tips of banana variety 'Agra'
}

\author{
D.A. Shirani ${ }^{1^{*}}$, K.A.C. Niroshani ${ }^{1}$, A.W. Gaminie ${ }^{2}$ and P.D. Abeysinghe ${ }^{3}$
}

\begin{abstract}
Fusarium wilt disease is the main threat to the commercial cultivation of kolikuttu (silk) banana (Musa spp.). Therefore, efforts were made to improve Kolikuttu banana through induced mutation to enable development of tolerant varieties to Fusarium wilt disease. Shoot apices of in-vitro proliferated banana variety 'Agra' were treated with a series of ethyl methanesulfonate (EMS; 0, 0.5, 1.0, 1.5, 2.0, 2.5 and 3.0\% v/v) along with two incubation periods ( $2 \mathrm{~h}$ and $3 \mathrm{~h}$ ) to identify the optimum concentration of the mutagen. The estimated $\mathrm{LD}_{50}$ values, based on the survival percentage, were $2.63 \%$ and $1.6 \%$ for $2 \mathrm{~h}$ and $3 \mathrm{~h}$, respectively. Fresh weight was reduced by $50 \%$ of the control at EMS concentrations of $1.58 \%$ and $1.27 \%$ while $L_{50}$ values for shoot height reduction were $1.71 \%$ and $1 \%$ for $2 \mathrm{~h}$ and $3 \mathrm{~h}$ immersions, respectively. Linear reduction of number of buds with increasing EMS dosages was much prominent with $2 \mathrm{~h}$ incubation and the estimated $\mathrm{LD}_{50}$ values for this parameter were $1.72 \%$ and $1.24 \%$ for $2 \mathrm{~h}$ and $3 \mathrm{~h}$ incubation, respectively. At lower dosage levels, the multiplication ratio over four subculture cycles showed considerable variations. Multiplication was completely arrested at dosages $>1.5 \%$.
\end{abstract}

Keywords: Banana, Kolikuttu, EMS, in-vitro, $\mathrm{LD}_{50}$, mutagenesis

\section{Introduction}

Banana (Musa spp.) plays an important role among the fruit crops in Sri Lanka in terms of extent of production and consumption. Banana variety 'Agra' is the recommended silk banana (Kolikuttu) variety by the Department of Agriculture (DOA). This variety is extremely susceptible to panama disease caused by the soilborne fungus, Fusarium oxysporium f.sp. cubense (Foc). Rajapakse et al. (2005) reported that $74 \%$ of Kolikuttu banana cultivated lands in the Hambantota district in the southern province of the country ( $<300 \mathrm{~m}$ amsl, annual rainfall $<1,200 \mathrm{~mm}$ ) were infected with panama disease. Banana improvement through conventional techniques is extremely difficult due to sterility and polyploidy. Somaclonal variation and induced mutation are considered as effective ways to improve banana and several varieties have been developed using these techniques (Roux, 2004; Smith et al., 2005).

In-vitro techniques can improve effectiveness of mutation induction in crops, and different types of explants such as shoot tips (Broertjes and van Harten, 1988)

\footnotetext{
${ }^{1}$ Agriculture Research Station, Telijjawila, Sri Lanka

${ }^{2}$ Grain Legumes and Oil crops Research and Development Centre, Angunakolapalassa, Sri Lanka

${ }^{3}$ Department of Botany, University of Ruhuna, Matara, Sri Lanka

*Corresponding Author: shirani_da@yahoo.com
} 
can be used as the disease-free starting materials (Kulkarni et al., 2007; Predrieri, 2001) for mutation. Both physical and chemical mutagens have been successfully used to create variations and ethyl methanesulphonate (EMS), which belongs to alkylating agent is the most widely used chemical mutagen which has been used effectively for creating variations in many crops including banana (Berenschot et al., 2008; Krishna et al., 2016). Further, EMS is known to increase point mutation (gene mutations) rather than chromosomal changes (Jabeen and Mirza, 2002; Toker et al., 2007) when compared to physical mutagens.

Selection of a suitable dosage of mutagen is one of the most critical factors in any induced mutation programme. The effective dosage is identified as the concentration of mutagen together with incubation period at a particular temperature. The optimum dosage may also be depended on the genetic factors (Bidabadi et al., 2012; Kodym and Afza, 2003), size of the explant, age of the culture and condition of the explant. Even for the same genomic group different scientists have found diverse dosages for in-vitro shoot tips of banana. Omar et al. (1989) suggested $24.69 \mathrm{mM}$ plus $3 \mathrm{~h}$ incubation for AAA group (cv. Grande Naine-60A) while Jankowicz-Cieslak et al. (2012) selected $1 \%(92.34 \mathrm{mM})$ and $3 \mathrm{~h}$ incubation for the same genomic group (cv. Grande Naine) depending on percentage reduction in fresh weight. Therefore, the present study was carried out to identify the most effective EMS dosage for mass treatment of shoot apices of in-vitro multiplied banana variety 'Agra' in in-vitro mutagenesis research programme of Kolikuttu banana to achieve Fusarium wilt resistance or tolerance.

\section{Materials and Methods}

Shoot tip cultures of Kolikuttu banana (Musa spp.) variety 'Agra' were initiated from sward suckers of healthy field grown mother plants. The cultures were multiplied over eight subculture cycles through clumps of buds on solid MS medium (Murashige and Skoog, 1962) supplemented with $4 \mathrm{mg} / \mathrm{L} \mathrm{BAP}$ and $2 \mathrm{mg} / \mathrm{L} \mathrm{IAA}$ once in every 4-5 week intervals. The shoot apices were dissected from shoot clusters and trimmed to a size of approximately 5-7 $\mathrm{mm}$ by removing several sheathing leaves and leaving 2-3mm corm tissues before treating with EMS.

Two separate experiments were conducted to find out suitable dosage to treat shoot tips. Working solutions of EMS (0, 0.5, 1 and 1.5, 2, 2.5 and 3\%) were prepared using a $10 \%(\mathrm{v} / \mathrm{v})$ EMS (Sigma, 0880) solution. The incubation periods tested were $2 \mathrm{~h}$ and $3 \mathrm{~h}$. Dimethyl sulfoxide (DMSO) at $2 \%$ was incorporated to each flask containing EMS as a career agent. A total of 30 excised shoot apices per treatment were submerged in mutagen solution and controls as $0.5 \mathrm{ml} / \mathrm{shoot}$ apex for different incubation periods. The experiments were conducted along with $2 \%$ DMSO using similar number of shoot apices as control. All treatments were carried out at $26^{\circ} \mathrm{C}$ and incubation was done on an orbital shaker at $80 \mathrm{rpm}$. Following EMS treatment, shoot apices were rinsed three times with sterile distilled water and allowed to dry on a sterilized filter paper for a while. The EMS-treated shoot apices were cultured 
on solid MS medium as 3 explants per vessel. Cultures were maintained at $26 \pm 1{ }^{\circ} \mathrm{C}$ with 12/12 Day/Night photoperiod for 40 days. The survival of explants was recorded at each ten days up to 40 days.

After 40 days, the fresh weight, shoot height and number of buds were recorded and sub-cultured on to same medium. Shoots were sub-cultured once in 4-5 weeks for 3 cycles $\left(M_{1} V_{3}\right)$. At each cycle, the survival of explant and rate of proliferation in terms of number of buds was recorded. After the $3^{\text {rd }}$ sub-culturing, the shoots were transferred to hormone-free solid MS medium (M1V4) to facilitate the growth of shoots and in-vitro rooting. The survival percentage of control and growth reduction percentage at 50\% were calculated employing regression analysis (SAS 9.1) of replicated data. Growth was measured with fresh weight and height of the plant using 08 randomly selected vessels each containing three rooted plantlets before establishment in pots for hardening and data were analysed using ANOVA.

\section{Results and Discussion}

\section{Survival of shoot tips}

High concentrations of EMS enhance the mutagenic events however, could make tissue damage while decreasing the survival percentage. The duration should be long enough to permit hydration and infusion of mutagen to the target tissue.

The survival of explant decreased linearly with increasing dosage for both incubation periods and the estimated regression coefficient (adj. $R^{2}$ ) was 0.98 . (Figure 1). Reduction in survival percentage was very high at $3 \mathrm{~h}$ incubation than $2 \mathrm{~h}$. At $3 \% \mathrm{EMS}$ plus $3 \mathrm{~h}$ incubation all the explants died showing the lethal effect. The $\mathrm{LD}_{50}$ values were determined as $2.63 \%$ and $1.6 \%$ at $2 \mathrm{~h}$ and $3 \mathrm{~h}$ incubation periods, respectively. The highest frequency of mutation can be expected at the dosage, which kills $50 \%$ of the shoot tips. However, at $\mathrm{LD}_{50}$ dosage, the multiplication and the shoot growth will be poor (Smith et al., 1994).

For physical mutagens, Roux (2004) has recommended dosages for gamma irradiation for different ploidy levels and genomic groups. However, such recommendations have not been made for chemical mutagens. For cultivar Grande Naine (AAA) 1.5\% EMS along with $4 \mathrm{~h}$ incubation treatment was found to be lethal for the shoot tips (Jankowicz-Cieslak et al., 2012).

\section{Growth parameters}

Determination of $\mathrm{LD}_{50}$ based on survival rate as the sole parameter could not be considered as appropriate in crop improvement programmes through induced mutation. As reviewed by Roux (2004) the survival rate always indicated higher optimal dose than other parameters. The survived shoot tips may remain dormant without regenerating buds and the growth of shoot tips could be very poor when treated with higher doses of mutagens. As such, there will be no sufficient plants left to detect mutations after three subculture cycles. 


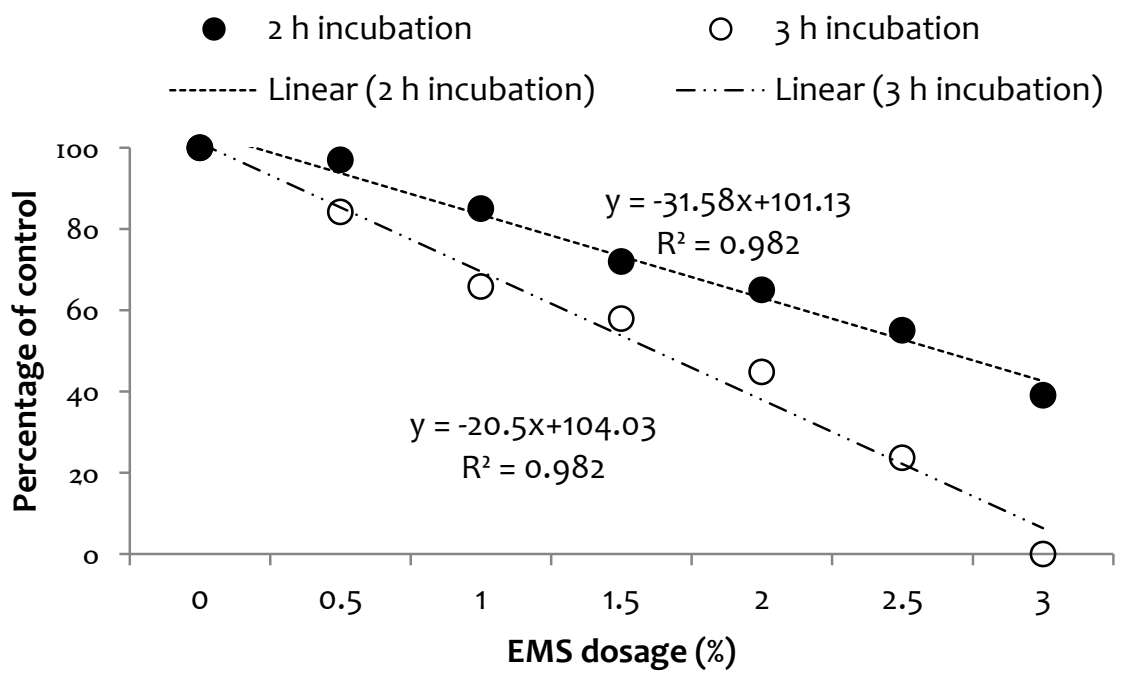

Figure 1. Percentage survival of shoot tips of the banana variety 'Agra' under different EMS concentrations and 2 and $3 \mathrm{~h}$ incubation

Smith et al. (2006) used 20Gy as optimum dosage in spite of its $L_{50}$ at $30 \mathrm{~Gy}$ to treat micropropagated shoot tips of 'Williams' banana to make this technique practical on large scale. Bhagwat and Duncan (1998a) recommended optimum EMS dosage with $80 \%$ explant survival for the shoot apices of $\mathrm{cv}$. Highgate (AAA). Jankowicz-Cieslak et al. (2012) used optimal dose of EMS at $1 \%$ for bulk treatment of shoot tips based on fresh weight reduction percentage of in-vitro plantlets of cv. 'Grande Naine' (AAA).

The mean values of all the 3 parameters measured; fresh weight, shoot height and number of buds (data not shown) were comparatively higher with $2 \mathrm{~h}$ immersion than $3 \mathrm{~h}$. According to Roux (2004), estimation of the $\mathrm{LD}_{50}$ value based on fresh weight data was preferred due to less experimental error in spite of its risk in contamination and requirement of high labour. Significant reduction $(p<0.05)$ of the percentage fresh weight was observed with EMS treatment under both incubation periods. The high regression coefficients ( 0.93 and 0.85 for $2 \mathrm{~h}$ and $3 \mathrm{~h}$ immersions, respectively) indicated that fresh weight and dose had an inverse but close association (Figure 2 ). The calculated $\mathrm{LD}_{50}$ values were $1.58 \%$ and $1.27 \%$ for $2 \mathrm{~h}$ and $3 \mathrm{~h}$, respectively.

In selecting optimum concentration of a chemical mutagen, number of buds or the proliferation of bud is important when the necessity of speediness of cloning variants is considered. In the present study the correlation between EMS concentration and regeneration of buds was more significant in shoot tips treated for $2 \mathrm{~h}$ (regression coefficient of $0.96(\mathrm{CV}=9.75 \%)$ ) as compared to $3 \mathrm{~h}$ incubation (regression coefficient $0.87 ; \mathrm{CV}=20.97 \%$ ). The calculated $\mathrm{LD}_{50}$ values for this parameter were $1.72 \%$ and $1.24 \%$ for $2 \mathrm{~h}$ and $3 \mathrm{~h}$, respectively (Figure 3 ) and the results were in par with the findings of Bidabadi et al. (2012). 


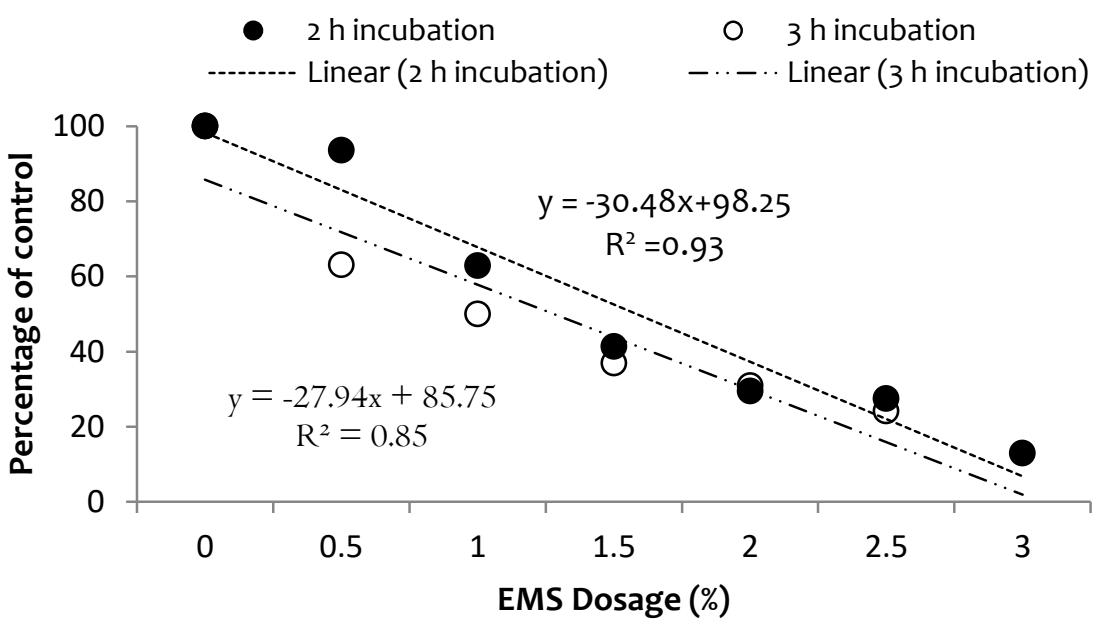

Figure 2. Fresh weight (as a percentage against the untreated control) of the shoot tips of banana variety 'Agra' 40 days after treatment with different EMS concentrations and 2 and 3 $\mathrm{h}$ incubation

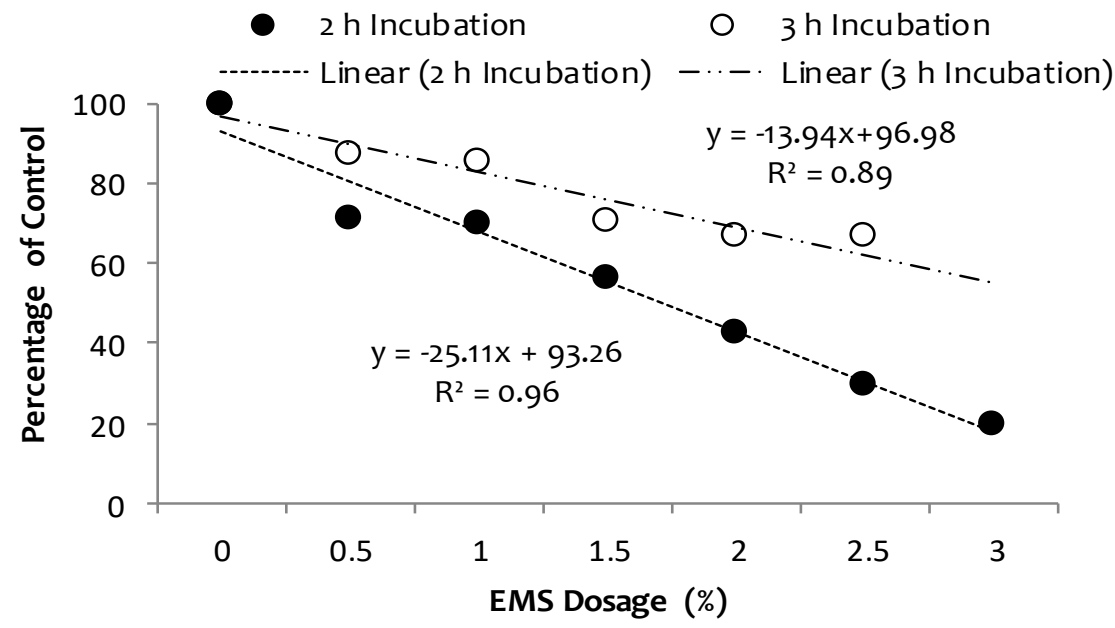

Figure 3. Number of buds (as a percentage against the untreated control) of the shoot tips of banana variety 'Agra' 40 days after treatment with different EMS concentrations and 2 and 3h incubation

Regression analysis showed EMS treatment significantly affected growth in terms of height (Figure 4). For $2 \mathrm{~h}$ incubation (adj. $R^{2}=0.95, C V=13.31 \%$ ) the $L D_{50}$ value was $1.71 \%$ whereas for 3 h duration $\left(R^{2}=0.85, C V=27.02 \%\right)$ the estimated $L_{50}$ was $1 \%$. Higher CV values for this parameter indicated considerable variations among replicates. 


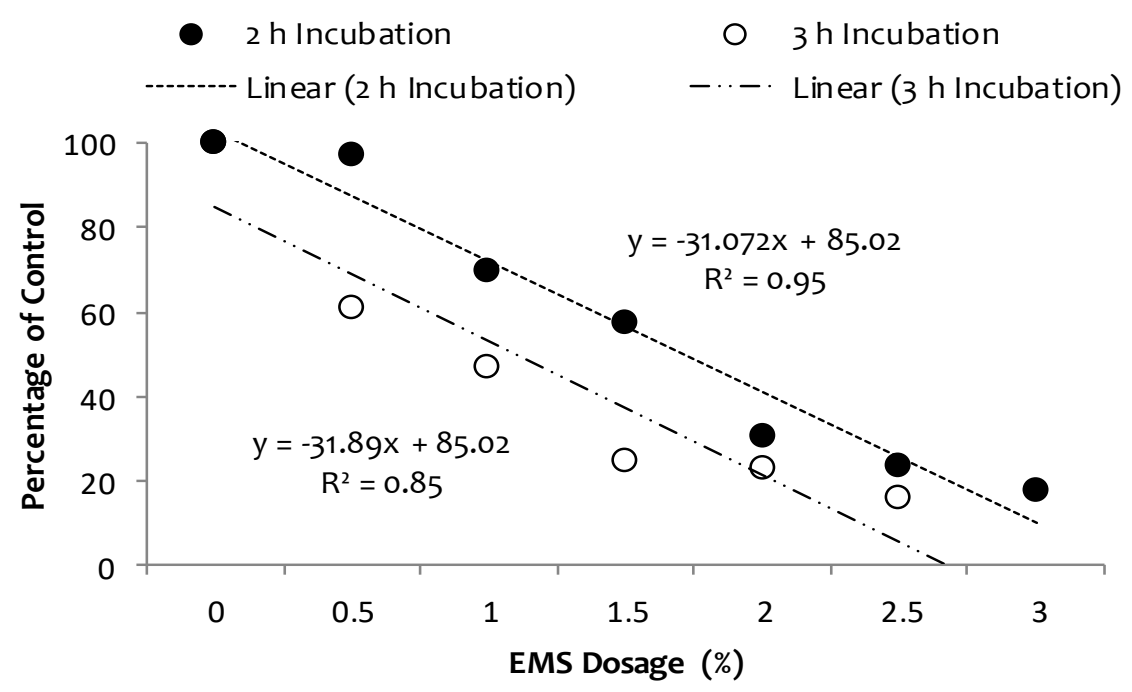

Figure 4. Shoot height (as a percentage against the untreated control) of the shoot tips of banana variety 'Agra' 40 days after treatment with different EMS concentrations and 2 and 3 $\mathrm{h}$ incubation

At $2 \%$ and $2.5 \%$ of EMS concentrations, the multiplication rates were $1: 1$ indicating no proliferation of buds in first 2 subculture cycles (Table 1). Those buds might have remained dormant throughout the first 2 subculture cycles, which is a quite common phenomenon after mutagen treatment (Bidabadi et al., 2012). At $3^{\text {rd }}$ subculturing all the shoot tips have been necrosed showing higher dosage of EMS were lethal. It was observed that all surviving shoot tips in other treatments were not able to multiply and they remain dormant throughout the subculturing. It could be the reason for comparatively low multiplication ratios at 1 and 1.5\% EMS treatment.

Kulkarni et al. (1997) experienced same results in their experiment with gamma irradiated shoot tips of different varieties of banana. According to the results of present experiment the dosages beyond $1.5 \%$ caused significant reduction in growth of the shoot tips. However, with lower dosages (0, 0.5 and 1\%) of EMS, the rates of multiplication did not show any dependence on either dosage or subculture cycle. The multiplication ratios of tips treated with $0.5 \%$ EMS showed better multiplication than controls. It may be due to favorable effect of mutagen at lower dosages, which have been observed by some scientists (Noordin et al., 2014; Rao et al., 1998). Occurrence of variation in multiplication ratios of mutated populations has been reported by Kulkarni et al. (1997). Multiplication ratio can be affected by several factors other than the EMS treatment like apical dominance, imbalanced distribution of chimeric and non-chimeric sectors resulting in differential growth rates, subculture cycle and somaclonal variations etc. It may also be due to limited no. of shoot tips treated in the present experiment. A clear picture could be drawn if large no. of shoot tips were treated. 
Table 1. Multiplication ratios of in-vitro cultures of the banana variety 'Agra' treated with EMS and incubated for $3 \mathrm{~h}$

\begin{tabular}{lccccc}
\hline \multirow{2}{*}{ Generation } & \multicolumn{5}{c}{ EMS Dosage (\%) } \\
\cline { 2 - 6 } & 0 & 0.5 & 1.0 & 1.5 & 2.5 \\
\hline M1Vo-M1V1 & 1.76 & 1.10 & 1.43 & 1 & 1 \\
M1V1-M1V2 & 2.09 & 3.25 & 1.52 & 1 & 1 \\
M1V2-M1V3 & 1.83 & 2.00 & 1.93 & 0 & 0 \\
M1V3-M1V4 & 3.23 & 3.40 & 2.36 & 0 & 0 \\
\hline
\end{tabular}

Significant differences were observed among treatments and indicated that growth was poor in EMS-treated plants (Table 2). Untreated plants and treated plants with $0.5 \%$ EMS had statistically similar fresh weights but they had different shoot heights. At 1 and 1.5\% EMS levels statistically same fresh weights and shoot heights were observed. Higher CV values reflect considerable variation in growth among replicates (vessels containing three plantlets). It was also noticed that the plantlets produced at higher concentration (1.5\%) of EMS were weaker and had low survival during hardening than the control plants. Morphological and chlorophyll variations during early growth stage were observed in treated plants.

Table 2. Growth of in-vitro plantlets of the banana variety 'Agra' treated with EMS and incubated for 3 h at transferring for hardening

\begin{tabular}{ccc}
\hline EMS Dosage (\%) & Mean shoot height & Mean fresh weight $(\mathrm{g})$ \\
\hline 0 & $6.14^{\mathrm{a}}$ & $1.48^{\mathrm{a}}$ \\
0.5 & $6.06^{\mathrm{a}}$ & $1.18^{\mathrm{b}}$ \\
1.0 & $3.58^{\mathrm{b}}$ & $0.56^{\mathrm{c}}$ \\
1.5 & $2.70^{\mathrm{b}}$ & $0.52^{\mathrm{c}}$ \\
CV\% & 18.63 & 24.86 \\
\hline
\end{tabular}

Within a column means followed by the same letter are not significantly different at $\mathrm{p}=0.05$.

\section{Conclusion}

EMS caused significant reduction of survival, growth and multiplication of shoot tips of banana variety 'Agra'. Higher LD $_{50}$ values; $2.63 \%$ and $1.6 \%$ with $2 \mathrm{~h}$ and $3 \mathrm{~h}$ incubation, respectively, were estimated for survival of shoot tips while lower $\operatorname{LD}_{50}$ values were calculated for reduction in fresh weight of shoot tip clusters, number of buds and shoot height. As the induction of variations by mutagenic treatment for desired mutants is by chance, it would be safer to choose a range of dosage that cause less tissue damage and give higher growth and multiplication. Based on different $L D_{50}$ values the suitable dose range could be identified as 1 to $1.2 \%$ of EMS with $3 \mathrm{~h}$ immersion. For $2 \mathrm{~h}$ immersion a range of $1.5-1.7 \%$ of EMS could be used. 


\section{Acknowledgement}

The first author wishes to thank Sri Lanka Council for Agricultural Research Policy for funding this study under NARP. Sincere thanks are due to Prof. (retired) L. Nugaliyadde and Dr. (Ms.) M.M. Nugaliyadde for their valuable comments to improve the manuscript.

\section{References}

Berenschot, A.S., Zucchi, M.I., Tulmann-Neto, A. and Quecini, V. (2008): Mutagenesis in Petunia $x$ hybrida Vilm and isolation of a novel morphological mutant. Brazilian J. Plant Physiol. 20: 95-103.

Bhagwat, B. and Duncan, E.J. (1998a). Mutation breeding in banana cv. Highgate (Musa spp. AAA group) for tolerance to Fusarium oxysporum f. sp. Cubense using chemical mutagens. Sci. Hort., 73: $11-22$.

Bidabadi, S.S., Meon, S., Wahab, Z., Sreeramanan, S. and Mahmood, M. (2012): Induced mutations for enhancing variability of banana (Musa spp.) shoot tip cultures using ethyl methanesulphonate (EMS). Aust. J. Crop Sci., 6(3): 391-401.

Broertjes, C. and van Harten, A.M. (1988): Applied mutation breeding for vegetatively propagated Crops. Elsevier, Amsterdam.

Jabeen, N. and Mirza, B. (2002): Ethyl methanesulfonate enhances genetic variability in Capsicum annuum. Asian J. Plant Sci.,1: 425-428.

Jankowicz-Cieslak, J., Huynh, O. A., Brozynska, M., Nakitandwe, J. and Till, B. J. (2012): Induction, rapid fixation and retention of mutations in vegetatively propagated banana. Plant Biotechnol. J., 10: 1056-1066.

Kodym, A. and Afza, R. (2003): Physical and chemical mutagenesis. In: Plant functional genomics: methods and protocols. Methods in Molecular Biology. (Grotewold, E. Eds.). pp. 189 - 203 Humana Press, Inc., Totowa.

Krishna, H., Alizadeh, M., Singh, D., Singh, U., Chauhan, N., Eftekhari, M. and Sadh, R.K. (2016): Somaclonal variations and their applications in horticultural crops improvement. 3 Biotech. 6: 54-71.

Kulkarni, V.M., Ganapathi, T.R., Suprasanna, P., Bapat, V.A. and Rao, P.S. (1997): Effect of gamma irradiation on in vitro multiple shoot clusters of banana (Musa species). J. Nucl. Agric. Biol., 26(4): 232-240.

Murashige, T. and Skoog, F. (1962): A revised medium for rapid growth and bioassays with tobacco tissue cultures. Physiol. Planta., 15: 473-497.

Noordin, N., Ibrahim, R., Sajahan, N.H.M., Moosa, S. and Hussein, S. (2014): Effects of acute and chronic gamma irradiation on in vitro growth of Stevia rebaudiana Bertoni. IAEA online publication.

Omar, M.S., Novak, F.J. and Brunner, H. (1989): In vitro action of ethyl-methanesulphonate on banana shoots tips. Sci. Hort., 40: 283-295.

Predieri, S. (2001): Mutation induction and tissue culture in improving fruits. Plant Cell Tiss. Org. Cult., 64: $185-210$.

Rajapakse, R.G.A.S., Sakalasuriya, S.M.I.S.K., Kahawatta, J., Sumanapala, R.V. and Edirimanna, E.R.S.P. (2005): Identification of races of Fusarium wilt pathogen of Banana in Sri 
Lanka and selection of resistant germplasm. Annals Sri Lanka Depart. Agric., 7: 225232.

Rao, P.S., Ganapathi, T.R., Bapat, V.A., Kulkarni, V.M. and Suprasanna, P. (1998): Improvement of banana through biotechnology and mutation breeding. IAEA Publication. 107-118.

Roux, N.S. (2004): Mutation induction in Musa - review. In. Banana improvement: cellular, molecular biology and induced mutations. (Jain, S.M. and Swennen, R. Eds.) pp 23-32. Enfield, NH: Science Publishers.

Smith M.K., Hamill S.D., Becker D.K. and Dale J.L. (2005): Musa spp. Banana and plantain. In: Biotechnology of fruit and nut crops. (Litz, R.E. Eds.). pp 366-392. CAB International, Wallingford, UK.

Smith, M. K., Hamill, S. D., Langdon, P. W., Giles, J. E., Doogan, V. J. and Pegg, K. G. (2006): Towards the development of a Cavendish banana resistant to race 4 of fusarium wilt: gamma irradiation of micropropagated Dwarf Parfitt (Musa spp., AAA group, Cavendish subgroup). Aust. J. Exp. Agric., 46: 107-113.

Smith, M.K., Hamil, S.D., Langdon, P.W. and Pegg, K.G. (1994): Mutation breeding for banana improvement in Australia. In: The improvement and testing of Musa a global partnership. (Jones, D.R. Eds.). pp 233-242. INIBAP Publication.

Toker, C., Yadav, S.S. and Solanki, I.S. (2007): Mutation breeding. In: Lentil - an ancient crop for modern times: (Yadav et al. Eds). pp. 209-224. Springer, Germany. 
Shirani et al. 